\title{
The Translatability of Metaphor in Political Speeches from English into Arabic
}

\author{
Amal Ibraheem Al-Zou'bi \\ Lecturer \\ Yarmouk University \\ Mahmoud Kanakri \\ Prof. of Linguistics and Translation \\ Yarmouk University
}

\begin{abstract}
The study aims at investigating the problems and challenges of translating metaphors in political speech from English into Arabic. Five speeches of Presidents Barak Obama and Donald Trump were selected as a source of data in the study. A translational test was designed and administered in this study. It includes thirty excerpts of metaphors randomly selected from the aforementioned speeches. It was given to forty students enrolled in the M.A. program of translation at Yarmouk University in the academic year 2015/2016. Lakoff and Johnson's (1980) Conceptual Metaphor Theory was employed as a theoretical framework of this study. The findings of the study showed that there are a large number of inadequate and grotesque translations provided by the participants due to their absence of attention and unfamiliarity with political expressions. Due to this invidious picture, the researchers recommended amending the translation syllabus at Yarmouk University to add specialized courses in translating political speeches and metaphor for MA translation students. It also recommended conducting richer and deeper empirical studies about translating metaphors especially in political texts.
\end{abstract}

Keywords: political speech, metaphor, metaphor theory, M.A. students of translation.

\section{Introduction}

Translation is an ancient activity and an important tool which was created to ease communication between peoples who are different in their languages and cultures. Mardirosz (2014: 160) says that " translation is not just the expression in the target language of what has been expressed in the source language (preserving semantic and stylistic equivalences), but a more creative activity that enriches the source text with new ideological and cultural features".

According to Newmark(1980), translation is an operation where in lexis and grammar of the source text are replaced by equivalent lexis and grammar of the target text, in order to ease understanding the meaning of the source language by the target readers. Translation promotes human experience. Because of the existence of translation, global works and books are known to people all over the world. So, the role of translation enables the diffusion of new ideas in different cultures and spreads knowledge everywhere. However, as long as translation is essential, it is not an easy process or action.

On the definition of translation, Newmark (1980: 86) states that translation " is a craft consisting in the attempt to replace a written message and/or statement in another language", This means that the translation may be complicated since the translator should render the equivalent meaning of the source word in the target one, as he should have enough experience in the target culture in order to be able to reach the intended meaning for the target reader. In other words, translation renders the meaning of the (ST) source text into the (TT) target text, and focuses on the simplicity of understanding the translated text, as well in one language as well in another.

\section{Cultural Challenges in Translating Political Texts}

Political translation is a vital bridge in international relations, and it is very sensitive and highly demanding translation activities, as it concerns international relations. Yang (2012) notices that political translation plays a main role in translating language, and cultural exchanges.

One of the problematic areas in translation is politics; to translate political texts from one language into another is a hard and sometimes a cumbersome task due to cultural diversities. 
Thus, translators who endeavor to translate political texts should be familiar with both the source language and the target language, as well as with the subject itself, to perform the translation process successfully. Without these requirements, the texts handled would be rendered inappropriately.

Translations must adequately render the meaning of words and expressions from the source language, without losing any of their cultural connotations. Newmark (1988) discusses the problems in translating political texts in the light of differences of cultural terms between the source language and the target language, which can be solved by replacing a cultural word in the source text by equivalent one in the target text. He also introduces (1988: 136) a term he called "Cultural Word" where the readership cannot easily understand, and the strategies of translation for this kind of concepts depend on the particular text-type, requirements of the readership, and the importance of the cultural word in the text.

Nida (1964:160) observes a point

"Where the linguistic and cultural distances between source and receptor codes are least, one should expect to encounter the least number of serious problems, but as a matter of fact if languages are too closely related one is likely to be badly deceived by the superficial similarities...".

Nida (1964) also points out that the differences between a SL and a TL and the diversity of their cultures bring the difficulty and the challenge in the translation process. Further, the existence of cultural differences between two languages causes a problem to transfer the meaning, which exposes translation to failure.

\section{Political Discourse Analysis}

Political discourse is "a complex form of social activity" (Chilton and Schaffner, 1997: 207). Political discourse has become one of the most important elements in peoples' thoughts and behaviors, especially in the current events and conflicts, which demand studying the political discourse in order to offer a better understanding for the current political situation in the World. Al-Harahsheh (2013) states that political discourse is a written or spoken language used in order to influence people's opinions and attitudes. This means that successful politicians aim at controlling people's thoughts and attitudes, and attracting receivers' emotions.

Political discourse relies on translation, which means that any wrong or inappropriate choice of a word in a context may lead to mistranslation. Fairclough's (1989) states that political discourse socially formed and aimed. According to Wilson (2003), one of the main goals of political discourse analysis is to seek out the ways in which language choice is manipulated for specific political effect.

Schaffner (1996) argues that political discourse can be based on two criteria: functional and thematic. She (ibid) points out that political discourse is a result of politics, and it is historically and culturally determined. It fulfills various functions due to variety of political activities. Further, it is thematic because its topics are primarily related to politics such as political activities, political ideas and political relations.

\section{Political Metaphor and its Persuasive Power}

Penninck (2014) suggests that metaphor is a highly used as rhetorical instrument in crisis speech. Lakoff (1993: 1) states that "in classical theories of language, metaphor was seen as a matter of language not thought." That is metaphorical expressions relate exclusively to everyday language.

This study investigates the translatability of metaphors in the political field. Politics is the art of persuasion. It aims at manipulating the public opinion in order to govern a country, especially through a democratic election system. So, politicians, mostly, use metaphors as a mean of persuasion in their speeches before their populations as metaphors play important influence on people's thoughts and emotions, which may change their opinions in favor of a speaker. Aristotle considered metaphors as a decoration for texts (without affecting their meaning). Charteris-Black (2005:2) writes that the "choice of language in general and metaphor in particular is essential to their [politicians'] overall persuasiveness". This means that metaphors are necessary for successful leadership.

According to Beard (2000: 30) the purpose of political speeches is to manipulate listeners' opinions and emotions, and that the speaker only desires to gain or keep their power. The goal for politicians is primarily the persuasion and not to present facts. The speaker needs to use the audience language to attract the emotions and to affect them.

Newmark (1988: 113) shows different ways of translating metaphorical figures: "to search the same metaphor, to substitute it for other metaphor, to change it for comparison, to add an explanation, or to paraphrase it." 
To translate metaphors obviously, the translator should be familiar with the source and target languages. Dagut (1976:24) points out, the fact that "since a metaphor in SL is, by definition, a semantic novelty, it can clearly have no existing "equivalence" in TL".

Brevik (2008) states that: " the uniqueness of metaphors appears to be the one thing translation theorists can agree upon, and it seems a bit conceited to maintain that translating a phenomenon held to be so exceptional represents no challenge at all, and can be done by a simple word-for-word rendition. Nevertheless, the view that metaphors are untranslatable also seems a bit too extremist".

Translating metaphors in political speeches especially from English into Arabic can be a problematic matter for Arab translators due to the cultural differences between the two languages, here, Arabic and English, and to the variation between what metaphors appear to be and their vivid intended messages.

This study examines the translation of all types of metaphors in political speeches. The study aims to test the level of MA students in understanding the metaphors that are used in the five political speeches that received by Barak Obama and Donald Trump, and giving the functional meaning of these metaphors through the selected speeches, in order to widen the translation students' experience in translating political metaphors correctly.

Metaphors in political speech have not been tackled in the literature of translation. This study seems one of the conducted studies on metaphors of political leaders.

This study will answer the following questions:

1. What is the purpose are the metaphors used for, and to what extent they influence the audience?

2. What are the strategies of translation used by the chosen sample?

3. How about the challenges that the chosen sample of MA students encounter during the translation of political metaphors?.

\section{Literature Review}

This chapter reviews the relevant literature on the topic at hand. This involves examining related concepts, perspectives and findings from past researches that focus on the political speech and the translation of metaphor, translation of metaphor in political speech. In addition, the chapter discusses and sheds light on the relationship between metaphor and culture. Finally, the rationale for choosing the Conceptual Metaphor Theory will be presented.

\section{Conceptual Metaphor Theory}

Penninck (2014) states that Conceptual Metaphor Theory (CMT) is the most acceptable theory that relates metaphor to cognition. Deignan (2005:4) explains that this theory opposes the decorative method stating that metaphor "plays a central role in thought, and is indispensable to both thought and language". According to Kövecses (2005), conceptual metaphor consists of a set of agreements, or mappings, between a "target" and "source" domains. The meaning of particular metaphorical linguistic expressions is based on such correspondences or mappings.

This approach was first elaborated by Lakoff and Johnson, (1980) featured its main perceptions. According to them, everyday language is full of conventional metaphors. This is a great importance and shapes the cognition. Deignan (2005) believes that writers and researchers have concepts in their minds that they express through semantically related metaphors. These concepts are impacted by metaphors, because these help to grasp the meaning of a lot abstract notions such as emotions, ideas, plans, sociology, time, etc. that are only vaguely defined by what have experienced (Penninck, 2014)."In conceptual metaphors the more abstract, cognitively unavailable target domain is explained by means of a concrete and cognitively available one, viz. source domain via the process of mapping". (Lesz 2011: 13).

According to Penninck, (ibid) when the source domain is journey or building, we can draw metaphorical expressions through them in order to understand the target domain like mind. Thus, for Lakoff and Johnson (1980) people always try to understand these abstract concepts of which do not fully make sense by comparing them to concepts that are clearer in our experience or thought.

Lakoff and Johnson (1980) also state that metaphors originate from our earliest experiences in life. Which means that from our first day in the life, we use these universal experiences to think, which makes them shape part of our global perception. So, Goatly (2007) sees this thinking is universal, which makes all people understand and form part of the same "metaphorical language". Goatly, (ibid) also illustrates this idea by the metaphor "freedom is space to move". 
From our birth forth ward, we experience how much space we or other objects take in. Through this natural acquisition, this metaphor makes us understand the meaning of such abstract words as freedom.

\section{Data and Method of Analysis}

There are method and procedures that the present thesis followed. One of them is the Conceptual Metaphor Theory.

The data of the study were collected from five speeches: Two for President Barak Obama, and three for Donald Trump. They were related to election campaigns, terrorism and ISIS (Daish), in 2015.

Some metaphors from the five speeches were selected, and then analyzed for the purpose of pinpointing the political metaphors used and translated from English into Arabic. Then a random sample of MA students at Yarmouk University were asked to translate these metaphors from English into Arabic to test the translatability of metaphors in political speeches, and the informants' ability in giving the adequate meaning of them. The results were analyzed and tabulated and classified into adequate or inadequate translation, or no translation.

The instrument followed in this study is a translational test that includes30 metaphors from the speeches of president Obama and Donald Trump. The random sample of MA students at Yarmouk University were asked to translate them within the time of 1:30 by understanding the intention of using them (functional meaning).

A random sample of MA students were chosen. The whole number of students is 40 males and females.

\section{Theoretical Framework}

As a theoretical framework is essential for any study, he most accepted theory in this study is Lakoff and Johnson's (1980) Conceptual metaphor theory. Lakoff and Jonson assess that metaphorical language is used in people's everyday life and not like people think that metaphors are not essential in their life. Metaphors exist naturally in our thoughts, actions, and language, and used day-to-day in our life. Lakoff and Johnson (2003) argue that the human thought system is metaphorical; this means that the human conceptual system is metaphorically structured and defined.

According to them, our everyday language is full of conventional metaphors which shape our cognition. Lakoff and Johnson states that considering our conceptual system is full of metaphors, means that our everyday experiences, thoughts or actions are largely affected by metaphor.

For example, the conceptual metaphor the economic is building:

We're working with Iraq and the United Nations to help communities rebuild the security.

We are getting out of the nation-building business

We were pioneers of a modern-day banking system built on trust

Using the concept "Build" on economy which is structured by this conceptual metaphor is attracting to positive emotions. It represents the economy as the process of building a strong construction, where in every component is crucial to the stability of the whole. Lakoff\&Johnson (1980) state that metaphors originate from our earliest life. This means that from the day that we exist, we use the universal experiences to think, which makes them form part of our global perception.

So, the conceptual metaphor theory is the most suitable for metaphors we use in our everyday language. It concentrates our conceptual system which affecting thoughts.

\section{Findings and Discussion}

The findings of this study, as shown in the following table, indicate that $(45 \%)$ of the participants gave adequate translations, (30\%) of them provided inadequate translations, and (25\%) gave no translations.

\section{Adequate Translation}

The main challenge in translation is achieving "adequacy" between the SL text and the TL text. This means "Satisfactoriness the TL word, phrase, or sentence of the SL word, phrase, or sentence structurally and lexically". So, Al-Harahsheh and Obeidat (2015:10) define an adequate translation as: "the translation whereby the TL sentences are verbally and naturally restructured in Arabic to a great extent."

This section discusses the translations of the participants. After analyzing their translations, the researcher observes that reading the excerpts carefully and understanding it were the first reasons of producing adequate translations. The translators recognized that they should translate literally and when to translate functionally. 
Also, they used appropriate vocabularies, beside their cultural background that qualified them to translate adequately. The questionnaire of the study includes some metaphors which require the translator's familiarity and cultural experience with them.

Following are some examples on the adequate translations provided by the participants:

1) I hope everyone had a wonderful holiday weekend -- especially our men and women in uniform.

The adequate translations of the bold word "uniform" are:

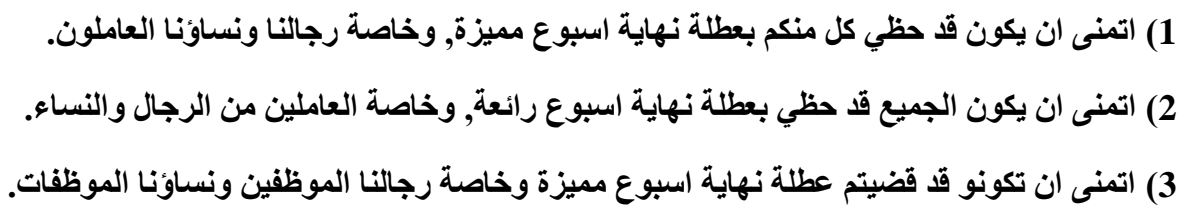

Eighty percent of the participants translated this excerpt adequately. The aforementioned three translations were provided functionally. As all of them lead to the same adequate meaning, the only difference between them is lexical. The translators in this excerpt did not translate literally because the literal translation of uniform means الزي الرسمي which is totally different from the intended meaning العاملين.

2) In many places in Syria and Iraq, including urban areas, it is dug among innocent civilian populations.

\section{It will take time to root them out.}

The adequate translations of the last sentence were:

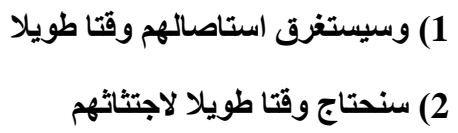

Sixty percent of the participants provided an adequate translation of this excerpt. The above mentioned literal translations were sufficient to render the adequate meaning. Both translations are the most appropriate interpretations of to root them out. The author used this expression in order to give an image that ISIL has roots between people and its existence had a long time, which needs to deracinate them radically. This gives the hearers a seriousness of this case.

3) And over the past year, we've seen that when we have an effective partner on the ground,

\section{ISIL can be pushed back.}

The proposed adequate translations of the bold phrase "ISIL can be pushed back" were:

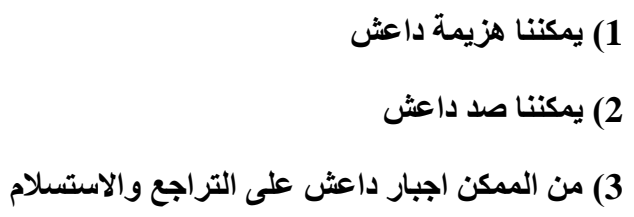

Forty seven and half percent of the participants translated this quote adequately. The metaphor used here is a physical, since the "pushing" is physical process. Both literal and functional translations are appropriate methods translators provided in order to give the intended meaning of the metaphor "pushed back" which has more than one meaning as "يتر اجعون, يستسلمون, يهزمون", as it can be noticed in "Arabic".

\section{Inadequate Translation}

The study found that misunderstanding some terms and expressions of the text leads translators to the mistranslation of the text. Also, some translators show muscles by performing translations unrelated to adequate meaning. Nord (2009: 3) states that: "a translation error is defined as a failure to carry out the instructions implied in the translation brief and as an inadequate solution to a translation problem". Nord (ibid) considers that cultural translation errors occur due to an inadequate decision regarding to reproduction or adaptation of cultural specific agreements. 
Some translators in this study did not recognize that the questionnaire includes metaphorical expressions which make them provide translations without considering if the expression or phrase is metaphor or just a plain speech.

Lexical choices are another problem leads to inadequate translation. Some translators face a problem while encountering more than one synonym for a word that makes them stray. The lack of their experience of using dictionaries appeared clearly in this study. For example, the phrase "The Beauty of America" in the nineteenth excerpt, according to context, does not accept any other translation than "سحر امريكا" or "روعة امريكا" Some translators, with their poor experience of using dictionary, lead them to produce totally different meanings like "الجمال الأمريكي".

1. The aforementioned notes should seriously considered by the translators. . I hope everyone had a wonderful holiday weekend -- especially our men and women in uniform.

The inadequate translations of the bold phrase were:

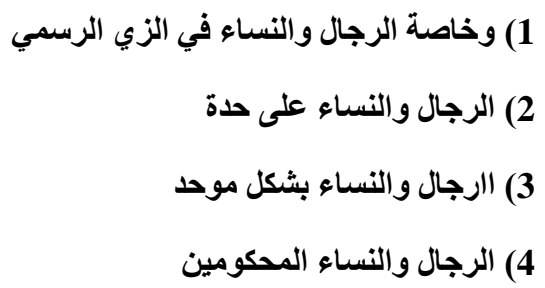

The study found that $17.5 \%$ of participants provided inadequate translations. The misunderstanding the sentence led some translators to give wrong translation of "uniform" by translating it literally in the first, second, and third answers. The forth answer points to the poor translator's experience of using dictionary.

2. In many places in Syria and Iraq, including urban areas, it's dug in among innocent civilian populations.

\section{It will take time to root them out.}

The inadequate translations of the last sentence were:

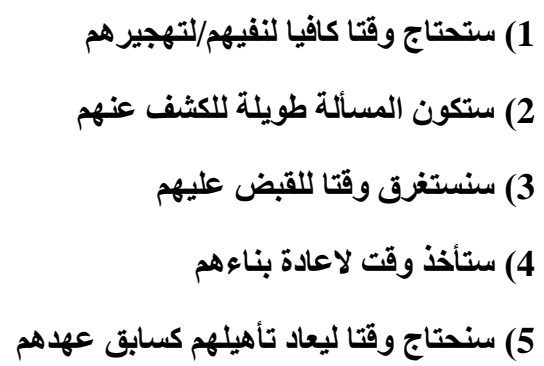

Only 30\% of translations were inadequate. The first three answers showed the law level of translators' experience in the

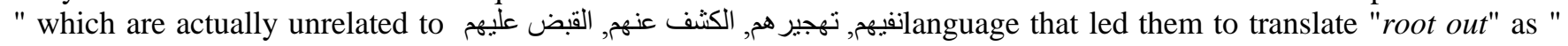
intended meaning. The fourth and fifth translations, with sorrow, revealed the lack in the experience of some translators in translating process. All given translations are inadequate and unrelated to the above mentioned excerpt.

3. And over the past year, we've seen that when we have an effective partner on the ground,

\section{ISIL can be pushed back.}

The bold phrase was translated inadequately as:

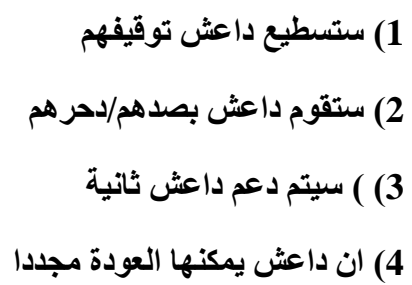


Forty two and half percent was inadequate translations. In the first two answers the unconsciousness of some translators led them to commit a disastrous mistake with changing the passive voice into active voice which makes ISIS the subject who will defeat the effective partner. The third and fourth answers mention the poor experience of translators in using phrasal verbs. Literal translation with conscious reading was enough to provide an adequate translation.

\section{Conclusions}

The thesis analyzed five famous modern political speeches delivered by Presidents Obama and Trump in order to shed light on the challenges that MA students of translation at Yarmouk University face while translating some selected metaphors. The study found a discomposing phenomenon that a large number of translators gave inadequate translations due to their absence of seriousness in handling the given texts, beside the challenges that translators encountered while dealing with political texts; they include metaphors and new expressions, beside the problem of choosing the right lexical items and shaping new concepts or sentences. The lack of their experience in language, culture, and using dictionaries play the main role in providing inadequate and invidious translations. These challenges lead the translators to use the wrong strategy in their translations, like using literal translation when the text needs the functional one and vice versa, which caused inadequate translations. On the other hand, there is a good number of the participants who were capable in gave the intended meanings in the study, which reflects their good experience.

According to the conclusion, it is concluded that the above mentioned challenges were due to the lack of comprehending texts, cultural background, experience of using language and using dictionaries, loyalty to SL and TL, and the lack of practice, which in total certainly lead to inadequate translations.

\section{Recommendations}

According to the results, the researchers suggest the following recommendations:

First, the study recommends that it is necessary to offer some specialized courses in translating political speech for MA translation students, that include new political expressions, neologisms, and metaphors coined in the world of politics. Besides collecting the new expressions as reference in the library of translation department,

Second, reading texts consciously, understanding contexts, and translators' sense are important factors leading the translators to choose the suitable render adequate translation. Translation is a profession can be improved by practice. As the translator read and translate more, as s/he acquires more experience and competency.

Third, the study also recommends conducting richer and deeper empirical studies about translating metaphors especially in political texts due to the importance of this domain in people's life.

Finally, the researcher suggests making competitions between students of translating new metaphors and expressions in new political speeches, and using the winning translation as a reference in order to enhance the ability of translation students. 


\section{Appendix One}

\begin{tabular}{|c|c|c|c|c|c|c|}
\hline Quoted No & Adequate & & Inadequate & & No-Transla & \\
\hline Excerpt & Frequency & Percentage & Frequency & percentage & Frequency & Percentage \\
\hline 1 & 32 & $80 \%$ & 7 & $17.5 \%$ & 1 & $2.5 \%$ \\
\hline 2 & 24 & $60 \%$ & 12 & $30 \%$ & 4 & $10 \%$ \\
\hline 3 & 19 & $47.5 \%$ & 17 & $42.5 \%$ & 4 & $10 \%$ \\
\hline 4 & 32 & $80 \%$ & 6 & $15 \%$ & 2 & $5 \%$ \\
\hline 5 & 18 & $45 \%$ & 16 & $40 \%$ & 6 & $15 \%$ \\
\hline 6 & 32 & $80 \%$ & 3 & $7.5 \%$ & 5 & $12.5 \%$ \\
\hline 7 & 21 & $52.5 \%$ & 9 & $22.5 \%$ & 10 & $25 \%$ \\
\hline 8 & 25 & $62.5 \%$ & 7 & $17.5 \%$ & 8 & $20 \%$ \\
\hline 9 & 12 & $30 \%$ & 14 & $35 \%$ & 14 & $35 \%$ \\
\hline 10 & 8 & $20 \%$ & 21 & $52.5 \%$ & 11 & $27.5 \%$ \\
\hline 11 & 25 & $62.5 \%$ & 5 & $12.5 \%$ & 10 & $25 \%$ \\
\hline 12 & 34 & $85 \%$ & 0 & $0 \%$ & 6 & $15 \%$ \\
\hline 13 & 23 & $57.5 \%$ & 15 & $37.5 \%$ & 2 & $5 \%$ \\
\hline 14 & 19 & $47.5 \%$ & 11 & $27.5 \%$ & 10 & $25 \%$ \\
\hline 15 & 13 & $32.5 \%$ & 10 & $25 \%$ & 17 & $42.5 \%$ \\
\hline 16 & 25 & $62.5 \%$ & 11 & $27.5 \%$ & 4 & $10 \%$ \\
\hline 17 & 17 & $42.5 \%$ & 6 & $15 \%$ & 17 & $42.5 \%$ \\
\hline 18 & 6 & $15 \%$ & 18 & $45 \%$ & 16 & $40 \%$ \\
\hline 19 & 7 & $17.5 \%$ & 22 & $55 \%$ & 11 & $27.5 \%$ \\
\hline 20 & 20 & $62.5 \%$ & 11 & $27.5 \%$ & 9 & $22.5 \%$ \\
\hline 21 & 5 & $12.5 \% \%$ & 7 & $17.5 \%$ & 28 & $70 \%$ \\
\hline 22 & 8 & $20 \%$ & 17 & $42.5 \%$ & 15 & $37.5 \%$ \\
\hline 23 & 25 & $62.5 \% \%$ & 7 & $17.5 \%$ & 8 & $20 \%$ \\
\hline 24 & 10 & $25 \%$ & 5 & $12.5 \%$ & 25 & $62.5 \%$ \\
\hline 25 & 22 & $55 \%$ & 11 & $27.5 \%$ & 7 & $17.5 \%$ \\
\hline 26 & 14 & $35 \%$ & 7 & $17.5 \%$ & 19 & $47.5 \%$ \\
\hline 27 & 34 & $85 \%$ & 0 & $0 \%$ & 6 & $15 \%$ \\
\hline 28 & 25 & $62.5 \%$ & 0 & $0 \%$ & 15 & $37.5 \%$ \\
\hline 29 & 28 & $70 \%$ & 0 & $0 \%$ & 12 & $30 \%$ \\
\hline 30 & 31 & $77.5 \%$ & 0 & $0 \%$ & 9 & $22.5 \%$ \\
\hline Total & 587 & $45 \%$ & 401 & $30 \%$ & 309 & $25 \%$ \\
\hline
\end{tabular}

\section{References:}

Al-Harahsheh, Ahmad. (2013). The Translatability of Figures of Speech in Khalid Mashaal's Political Speeches: A Critical Discourse Analysis. International Journal of English Linguistics. Vol. 3, No.3

Al-Harahsheh, A. Obeidat, M. (2015). A Critical Discourse Analysis Approach to the Challenging of Translating Parenthetical Sentences from English into Arabic in Political Texts: Joseph Nye's The Future of Power as a Model. International Journal of Translation. Vol. 27, (p 1-2).

Alverson, Hoyt. 1994. Universal Metaphors of Time in English, Mandarin, Hindi and Sesotho. John Hopkins University Press.

Basso, K. H. (1976). "Wise Words" of the Western Apache: Metaphor and Semantic Theory Meaning in Anthropology, Albuquerque Journal. New Mexico, (pp93-121). 
Bayram, Fith.(2010). Ideology and political discourse: A critical discourse analysis of Erdogan's political speech. Arecls Journal, UK. Vol. 7, (pp23-40).

Beard A (2000). The Language of Politics. London, Routledge.

Black, Max. (1976). Models and Metaphors, Studies in Language and Philosophy. Cornell University Press, UK.

Bornowsky,J. (1972). Science and human values. Harper Torch books, New York.

Brevik, Nina Elin. (2008). Translation theory with regards to translating metaphors. Lingualab.net. UK

Bughio, F. A. (2014) Critical Analysis of Political Discourse: A Study of Benazir Bhutto's Last Speech. Vol. 2. Baluchistan Journal of Linguistics, Pakistan.

Chilton. P \& Schäffner. C. (1997). Discourse and Politics. In Teun van Dijk (Ed.), Discourse Studies: A Multidisciplinary Introduction. Vol. 2. Discourse as Social Interaction (pp. 206-230). London, Sage.

Dagut, M. B. (1976). Can "Metaphor" Be Translated? Babel. Vol. 22. (1). (p24).

Deignan, A. (2005). Metaphor and corpus linguistics. Vol. 6. John Benjamins Publishing, Amsterdam.

Diermeier, D. Godbout, J. F., Yu, B., \& Kaufmann, S. (2012). Language and ideology in Congress. British Journal of Political Science, Vol. 42(01), (pp31-55).

Fairclough, N. (1989) Language and Power. Longman: London.

Fairclough, Isabela and Norman. (2012). Political Discourse Analysis. Rutledge, London \& New York.

Ghazala, H. ( 2004). Essays in Translation and Stylistics. Dar El-Ilm Lilmalayin, Beirut.

Goatly, A. (2007).Washing the Brain: Metaphor and Hidden Ideology. John Benjamins Publishing Company, Amsterdam, Philadelphia.

Griswold, D. (2007). The politics of speech: engendering the public sphere. Carnegie Mellon University, Pennsylvania, USA.

Habwe JH (2010). Dialogue Drama in Kenyan Political Speeches and Its Pragmatic Implications. Nordic Journal of African Studies, Finland. Vol. 19(3), (pp165-180).

Hart, R. P. (2009). Campaign talk: Why elections are good for us. Princeton University Press.New Jersey, USA.

Hart, R. P., Childers, J. P., \& Lind, C. J. (2013). Political tone: How leaders talk and why. University of Chicago Press, Chicago and London.

Holland, D. Quinn, N. (1987): Cultural Models in Language and Thought. Cambridge University Press, Cambridge.

$\mathrm{Hu}$, X. (2010). A Study on Conceptual Metaphors in Presidential Inaugural Speeches. Kristianstad University, Sweden.

Irimiea, S. (2010). A Rhetorical and Comparative Study of The Victory Speeches of Barack Obama and Mircea Geoana. The Journal of Linguistic and Intercultural Education. Vol. 3, (p 41).

J, Charteris-Black. (2011). Politicians and Rhetoric. Palgrave Macmillan, London.

Karapetjana, I. (2011). Pronominal Choice in Political Interviews.Baltic Journal of English Language, Literature and Culture. University of Latvia, Riga. Vol.1. (p36).

Kövecses, Z. (2005). Metaphor in culture: Universality and variation. Cambridge University Press, UK.

Kövecses, Z. (2010) Metaphor and Culture, Acta Universitatis Sapientiae, Philologica. Vol. 2, (pp197-220).

Lakoff, G. \& Johnson, M. (1980). Metaphors we live by. The University of Chicago Press, Chicago.

Lakoff, G. (1993). The contemporary theory of metaphor. At the University Press, Cambridge.

Lesz, B. (2011). To shape the world for the better: an analysis of metaphors in the speeches of Barack Obama. (Unpublished Master's thesis). University of Tromsø, Norway. (p10).

Lin Ma and Aihua Liu. (2008). A Universal Approach to Metaphors, Intercultural Communication Studies XVII: Vol. 1.

Literary Devices Editors. (2013). Metaphor. Retrieved November 2014, from http://literarydevices.net/metaphor/

Manfred Schmidt-Schauß, Joachim Niehren, Jan Schwinghammer, and David Sabel. (2008). Adequacy of compositional translations for observational semantics. HAL archives-ouvertes, France. P (521-535).

Mandelblit, Neli. (1995). "The Cognitive View of Metaphor and its Implications for Translation Theory". Translation and Meaning. Part 3. Maastricht, University Press, Netherlands.

Mensah EO (2012). The Yutong bus: Representations of a new Ghanaian Political Metaphor. Theory Practice in Language Studies. Vol. 2(1). (pp118-125).

Merriam-Webster (2014).Metaphor. Retrieved January 10, 2014, from http://www.merriamwebster.com/dictionary/metaphor

Nafula, Kuloba. (2012). Translation Inadequecies in the English Version of Kinjeketile. Centre for Translation and Interpretation, University of Nairobi.

Newmark, P. (1981). Approaches To Translation. Pergamon Press, Oxford, N.Y. PP (84-96).

Newmark, P. (1988). A Textbook of Translation. Prentice Hall International, UK. PP(104-113).

Newmark, P. (1998). Approaches to Translation. Prentice Hall, New York.

Nida, E. (1964). Toward a science of Translating. Leiden, E.J. Brill 
Njogu SK (1994). Dialogic Poetry: Contestation and Social Challenge in East African Poetic Genres. A Bell and Howell Company, Michigan.

Nord, C. (2012). Functional Approaches to Translation. The Encyclopedia of Applied Linguistics. Iowa State University, USA.

Otieno, R. F. (2016). Metaphors in political discourse: A review of selected studies. International Journal of English and Literature. Vol. 7(2). P (21-26).

Oxford Dictionaries (2014). Metaphor. Retrieved on January 10, 2014, From http://www.oxforddictionaries.com/definition/english/metaphor

Penninck, H. (2014). An analysis of metaphor used in political speeches responding to the financial crises of 1929 and 2008. University of Gent. (p22).

Reiss, K. (1983). Adequacy and Equivalence in Translation. The Bible Translator. Vol. 34 (3). (pp. 301-308).

Richards, I.A. (1936). The Philosophy of Rhetoric. Oxford University Press, London.

Savoy, J. (2010). Lexical analysis of US political speeches. Journal of Quantitative Linguistics: UK. pp(123-141).

Schaffner, C. (1996) "Editorial: political speeches and discourse analysis", Current Issues in Language \& Society. Institute for the Study of Language and Society, Aston University, Birmingham. Vol 3(3), (pp.201-204).

Sim, Y. Acree, B. D., Gross, J. H., \& Smith, N. A. (2013). Measuring ideological proportions in political speeches. Mellon University, USA.

Teun A. Dijk V. (1993). What is Political Discourse Analysis? University of Amsterdam, Benjamin's.

Titscher, S. Meyer, M. Wodak, R. \& Vetter, E. (2000) Methods of text and discourse analysis. London: Sage.

Vestermark, IDA. (2007). Metaphors in Politics. A study of the metaphorical personification of America in political discourse. Luleå University of Technology, Sweden.

Wilson, John (2003). The Handbook of Discourse Analysis: Political Discourse. Oxford: Blackwell.

Wu, Y. (2009). On the Relationship between Metaphor and Cultural Models: with data from Chinese and English language. Metaphorik.de. Vol. 17, (pp115-134).

Yashar Mehdad, Matteo Negri, Marcello Federico. (2012). Evaluating MT adequacy without reference translations. (pp 171-180). Association for Computational Linguistics, USA.

Yu, N. (1998): The Contemporary Theory of Metaphor. Vol. 1. John Benjamins Publishing Co: Amsterdam.

Yu N (2008). "Metaphor from body and culture". In W. Raymond and Jr. Gibbs (Eds.) Metaphor and Thought. London: Cambridge University Press. 